\title{
IMPLEMENTATION OF OPTIMUM ADDITIVE TECHNOLOGIES DESIGN FOR UNMANNED AERIAL VEHICLE TAKE-OFF WEIGHT INCREASE
}

\author{
Sven Maricic \\ Juraj Dobrila University of Pula ${ }^{1}$ \\ smaricic@unipu.hr \\ Iva Mrsa Haber \\ Juraj Dobrila University of Pula ${ }^{1}$ \\ visio@unipu.hr \\ Ivan Veljovic \\ Juraj Dobrila University of Pula ${ }^{1}$ \\ iveljovic@unipu.hr \\ Ivana Palunko \\ Department of Electrical and Computer Engineering \\ University of Dubrovnik \\ Laboratory for Intelligent Autonomous Systems \\ 4 Cira Carica, Dubrovnik, Croatia, 2220000 \\ lariat@unidu.hr \\ ${ }^{1}$ Institute of Science and Technology Visio \\ 30 Zagrebačka ulica, Pula, Croatia, 52100
}

\begin{abstract}
The aim of this paper is to investigate the possibility of drone optimization by selecting and testing the best material suitable for additive manufacturing technology and generative design approach, i. e. shape optimization. The use of additive manufacturing technology enables the creation of models of more complex shapes that are difficult or impossible to produce with conventional processing methods. The complex and unconventional design of the drone body can open up many possibilities for weight reduction while maintaining the strength of the drone body. By using 3D printing in addition to FEM (Finite Element Method) analysis, and generative design it can identify areas of the drone body that are overdrawn, allowing it to either lift off material or simply change the design at these areas. Choosing the right material for this application is crucial in order to optimise the mechanical properties of the material with weight, material cost, printability and availability of the material and the 3D printing method, while at the same time reducing environmental pollution. The goal is to reduce the drone mass by $15-20 \%$ using generative design tools. Mass is an important segment when prototyping a drone. If the drone is too heavy, more lift power is needed to keep the drone in the air, so the propellers have to turn faster and use more energy. Consequently, the reduction of drone mass should increase the take-off weight. In this article 5 commercial drones of similar characteristics are compared with the final proposal of our 3D printed drone (Prototype 1). The rotor distance between the drones, the weight of the electric motor and the take-off weight are compared. The goal was to produce a prototype with a big rotor distance-to-weight ratio, and take-off weight bigger than observed drones have.

The defined goal function was optimized in order to evaluate characteristics of 12 different 3D printed materials. Following properties: ultimate strength, stiffness, durability, printability of the material, and required bed and extruder temperature for printing were taken in consideration to select optimal material. Polycarbonate proved to be the best choice for 3D printing UAVs.
\end{abstract}

Keywords: additive technologies, unmanned aerial vehicle, shape optimization, generative design.

DOI: $10.21303 / 2461-4262.2020 .001514$

\section{Introduction}

Until a few years ago, the unmanned aerial vehicle (UAV) industry relied mostly on widely used conventional machining methods, which can often have a large carbon footprint. In recent decades, additive manufacturing (AM) offers a possible significant reduction in manufacturing costs, production with complex design and numerous advantages over «traditional» manufacturing [1]. 
AM technology can produce complex design that is impossible for achieving by using of conventional methods [2-6]. New geometries such as grids, cell structures in form of honeycombs and optimized structures with bionic look-a-like design can improve the overall performance of the aircraft [7-10].

UAVs are often used in various industrial and medical fields. Transporting the cameras and other photographic equipment allows various operations, as coastal surveying [11], agriculture monitoring [12, 13] fishing observing [14], forest monitoring [15], meteorological data acquisition [16], disaster monitoring, societal impacts and public safety [17-21], flood disaster monitoring [22], archaeological evaluation [23], surveillance, offensive, defensive manoeuvring and reconnaissance [24], building modelling for architectural usage [25] and supporting communication platforms [26].

Recent reports predict the number for UAVs will increase with the final shape and size depending on its main task [27]. UAVs raise their popularity in the military and maritime domains, from the use of heavy fuels to reduced logistical footprints and ease of maintenance [28]. Many civil industries are becoming aware of the tasks UAVs can complete. In 2019, the civil UAV market had a global volume of about 5.5 billion USD and the market for production and services applications is forecasted to grow at around $11 \%$ per annum over the next five to six years, largely driven by the infrastructure sector. Today's civil UAV market's categories are infrastructure inspection and maintenance, environment inspections and maintenance, and transportation and leisure. Some of the challenges $[29,30]$ that drones face vs conventional transportations are: the regulatory framework (lack of rules and standards regarding drone operations), availability of landing pads and charging pods, the high turnaround time between landing and take-off etc. Therefore, it is desirable to have the possibility to build low-cost UAVs for such applications [31]. Applying AM technology in UAV production can drastically reduce costs and significantly shorten development times [32]. AM offers further advantages for the manufacturing of UAVs: diverse polymeric materials that could lead to light construction. Layer-by-layer way of manufacturing allows complex forms application with free-form surfaces for the wings and tails [33]. Gregorski [34] proposed changes and planned new regulations of unmanned aerial vehicles in European and international law.

The use of topology optimization techniques presents the critical factor to minimize the weight of the components and to improve the productivity of the machines while preserving the structural requirements [35,36]. UAV industries ordinarily use composite materials [37], which combine advantages as, low weight, high strength, high corrosion, fatigue resistance and easy processing [38]. Recent trends include the use of graphite, Kevlar and glass fibre based composites for UAV applications [39, 40]. Carbon-fibre reinforced plastics (CFRP) stand out for the niche application of UAV.

Structural efficiency of a UAV can be improved via two methods, i. e. the use of lightweight structures and the use of high-strength-to-weight materials [41]. This paper's main goals are focused toward possible economic and ecological savings when new design has been applied. In addition, by using new technologies combined, enlarging take-off weight was calculated with aim of reduction operating cost (and improvement of the speed) of UAV design. The impact of the UAV technology parameters optimization was analysed and presented.

FEM analysis and topology optimization in the designing phase was used to minimize the components mass while preserving structural requirements. Merging topology optimization with additive manufacturing, enabled an optimal balance of strength and mass that results in the UAVs greater take-off weight.

Evaluating different materials (by optimization of the defined goal function) that can be 3D printed, different properties were taken in the calculation such as ultimate strength, stiffness, durability, printability of the material, and required bed and extruder temperature for printing the selected material. Taking all this into consideration, Polycarbonate proved to be the best choice for 3D printing UAVs.

The topic of Unmanned Aerial Vehicle (UAV) is of wide interest, and the significant number of existing publications to this topic, and the available developments proves so. In commercial applications UAVs have the potential to dramatically alter several industries. With their ability 
to collect data and transport loads, drones are re-shaping the way we think and feel about our physical environment [17]. Many researches of UAV wide applications have been conducted. From an efficient and cost-effective survey tool for topographic mapping and measurement in the coastal zone [11], monitoring crop fields with high tech sensing technology [12], reducing the costs to maintain a long-term local-scale monitoring [15], to developing, testing and verifying meteorological sensor package as payload for an already available carrier aircraft [16], and of course military and cargo applications [28].

New technologies and designing processes have also been researched to optimise the manufacturing and the design of the UAVs. The emerging technology of additive manufacturing is entering rapidly into the aerospace world and seems to be its future. Many manufacturing processes are replaced by this technology [9]. It's already shown that with the use of additive manufacturing more complex designs, and light-weight construction of UAV components can be made, offering several advantages compared to conventional manufacturing methods [33]. The challenge becomes to optimize the size, weight, and aerodynamics of the UAV based on the application [24], and this has also been the topic of many researches, as has been the topic of modular UAVs that can easily and quickly change its configuration [10].

The use of topology optimization techniques plays a key role to minimize the weight of the components and to improve the productivity of the machines [35]. Topology optimization is the process of determining the optimal layout of material and connectivity inside a design domain [36].

As it is possible to see, research in the field of UAV different applications, and in the field of using additive manufacturing and topology optimization in the design and manufacturing process of UAVs have already been made. However, no research has yet been done on choosing and testing the best material for 3D printing UAVs, and implementing topology optimization to compare results with the goal of reducing the overall UAV mass, while preserving the structural strength and safety factor.

\section{Materials and methods}

3D print technology enables users to choose almost optimal material for each designed model. Since one of the main goals in using this emerging manufacturing mode is to reduce environmental pollution, few materials for building UAV are presented and analysed. Designing UAV from recycled materials presents challenges in this fast growing area. Relatively small selection of recycled materials for 3D printing and its environmental effects can represent an obstacle in choosing the material with the best properties. According to literature [42], some of the activities are utilization of recycled plastics from bottles such as Polyethylene Terephthalate (PET), in order to rapidly print foldable UAV airframes. They synthesized different densities from carbon fibres by vacuum bag technique and analysed the material properties of commonly used 3D printing filaments with that of the recycled filament. Aurora pioneered in 2016 the use of 3D-printed composite parts reinforced with 25,4 mm-long carbon fibres for a new-development UAV [43]. Recent, many biodegradable 3D filaments (with a high percentage of organic material), made from recycled materials, have been developed to be environmentally friendly and have become alternatives to plastic filaments. UK 3D printing company Filamentive, in collaboration with Belgian recycling company, produced $100 \%$ recycled PET filament. Their goal is to transform European plastic waste into the usable filament [44]. Plastic materials are classified based on their recyclability. As shown in Table 1, there are 7 main classification groups for plastic materials.

Unfortunately, not all plastics are recyclable, reusable and accepted by different public recycling centres, therefore some of the proposed material for 3D printing the UAV in Table 2 will be easier to be recycled then others based on the classification type.

In presented case, for twelve proposed materials that had been evaluated, the value of the goal function was calculated, defined as the weighted average of different properties: $30 \%$ Ultimate strength, $20 \%$ Durability, $30 \%$ Density, $5 \%$ Price, $5 \%$ printability, $10 \%$ Recyclability (Table 2).

As can be seen from the Table 2, the maximum value of the goal function of 7.6 has been found for Polycarbonate material. According to the presented maximum value, this material presents the best choice for 3D printing UAV. 
Table 1

Plastic classification

\begin{tabular}{|c|c|c|c|}
\hline Identification code & Plastic type & Common application & Melting temperature \\
\hline PET & $\begin{array}{l}\text { Polyethylene } \\
\text { terephthalate } \\
\text { (PET, PETE) }\end{array}$ & $\begin{array}{l}\text { Packaging } \\
\text { Soft drink and water bottles } \\
\text { Electrical and electronic connectors and components } \\
\text { Appliance components } \\
\text { Shampoo and mouthwash bottles }\end{array}$ & $\operatorname{Tm}=250^{\circ} \mathrm{C}$ \\
\hline PE-H & $\begin{array}{l}\text { High-density } \\
\text { polyethylene } \\
\text { (HDPE) }\end{array}$ & $\begin{array}{l}\text { Detergent, bleach and fabric conditioner bottles } \\
\text { Transport cases } \\
\text { Pipes } \\
\text { Electrical fittings } \\
\text { Sports equipment } \\
\text { Food and freezer containers } \\
\text { Toys }\end{array}$ & $\operatorname{Tm}=130^{\circ} \mathrm{C}$ \\
\hline & $\begin{array}{l}\text { Polyvinyl } \\
\text { chloride } \\
\text { (PVC) }\end{array}$ & $\begin{array}{l}\text { Credit cards } \\
\text { Pipes for external use } \\
\text { Window and door frames } \\
\text { Sheet for roofing or panelling } \\
\text { Blown bottles for oil, wine } \\
\text { Synthetic leather products }\end{array}$ & $\operatorname{Tm}=240^{\circ} \mathrm{C}$ \\
\hline PE-LD & $\begin{array}{l}\text { Low-density } \\
\text { polyethylene } \\
\text { (LDPE) }\end{array}$ & $\begin{array}{l}\text { Film for packaging } \\
\text { Food containers } \\
\text { Flexible bottles } \\
\text { Irrigation pipes } \\
\text { Wire and cable applications }\end{array}$ & $\operatorname{Tm}=120^{\circ} \mathrm{C}$ \\
\hline PP & $\begin{array}{l}\text { Polypropylene } \\
\text { (PP) }\end{array}$ & $\begin{array}{l}\text { Automotive parts - bumper bars, ducts, fuel tanks } \\
\text { Food/packaging containers and boxes } \\
\text { Sterilisable hospital items } \\
\text { Ropes and fibres } \\
\text { Most bottle tops }\end{array}$ & $\operatorname{Tm}=173{ }^{\circ} \mathrm{C}$ \\
\hline PS & $\begin{array}{l}\text { Polystyrene } \\
\text { (PS) }\end{array}$ & $\begin{array}{l}\text { Egg cartons } \\
\text { Video cases } \\
\text { Low cost brittle toys }\end{array}$ & $\operatorname{Tm}=240^{\circ} \mathrm{C}$ \\
\hline 0 & $\begin{array}{l}\text { Other (often } \\
\text { polycarbonate } \\
\text { or ABS) }\end{array}$ & $\begin{array}{l}\text { Nylon (PA) } \\
\text { Acrylonitrile butadiene styrene (ABS) } \\
\text { Polycarbonate (PC) } \\
\text { Layered or multi-material mixed polymers }\end{array}$ & $\operatorname{Tm}=225^{\circ} \mathrm{C}$ \\
\hline
\end{tabular}

Table 2

The Goal function for chosen materials

\begin{tabular}{|c|c|c|c|c|c|c|c|}
\hline Material & $\begin{array}{c}\text { Ultimate } \\
\text { strength }[\mathrm{MPa}]\end{array}$ & $\begin{array}{l}\text { Dura- } \\
\text { bility }\end{array}$ & $\begin{array}{l}\text { Density } \\
{\left[\mathrm{g} / \mathrm{cm}^{3}\right]}\end{array}$ & $\begin{array}{c}\text { Price } \\
\text { per kg }[€]\end{array}$ & $\begin{array}{l}\text { Print- } \\
\text { ability }\end{array}$ & Recyclability & $\begin{array}{c}\text { Goal } \\
\text { function }\end{array}$ \\
\hline 1 & 2 & 3 & 4 & 5 & 6 & 7 & 8 \\
\hline \multirow{2}{*}{ ABS } & 40 & \multirow{2}{*}{8} & 1.04 & $8.5-35$ & \multirow{2}{*}{8} & Type 7 & \multirow{2}{*}{6.7} \\
\hline & 4 & & 9.25 & 8.75 & & 3 & \\
\hline \multirow{2}{*}{ TPU } & $26-43$ & \multirow{2}{*}{9} & 1.19 & $25-60$ & \multirow{2}{*}{6} & Type 3 & \multirow{2}{*}{6.8} \\
\hline & 3.5 & & 8.75 & 6.75 & & 7 & \\
\hline \multirow{2}{*}{ PLA } & 65 & \multirow{2}{*}{4} & 1.24 & $8.5-35$ & \multirow{2}{*}{9} & Type 7 & \multirow{2}{*}{6.4} \\
\hline & 6.5 & & 8.25 & 8.75 & & 3 & \\
\hline \multirow{2}{*}{ HIPS } & 32 & \multirow{2}{*}{7} & 1.04 & $20-27$ & \multirow{2}{*}{6} & Type 6 & \multirow{2}{*}{6.3} \\
\hline & 3.2 & & 9.25 & 8.5 & & 4 & \\
\hline
\end{tabular}


Continuation of Table 2

\begin{tabular}{|c|c|c|c|c|c|c|c|}
\hline 1 & 2 & 3 & 4 & 5 & 6 & 7 & 8 \\
\hline \multirow{2}{*}{ PETG } & 53 & \multirow{2}{*}{8} & 1.23 & $20-50$ & \multirow{2}{*}{9} & Type 1 & \multirow{2}{*}{7.5} \\
\hline & 5.3 & & 8.75 & 7.5 & & 9 & \\
\hline \multirow{2}{*}{ Nylon } & $40-85$ & \multirow{2}{*}{10} & 1.14 & $20-55$ & \multirow{2}{*}{8} & Type 7 & \multirow{2}{*}{7.5} \\
\hline & 6.2 & & 8.75 & 7.25 & & 3 & \\
\hline \multirow{2}{*}{$\begin{array}{l}\text { Carbon } \\
\text { fiber filled }\end{array}$} & $45-48$ & \multirow{2}{*}{3} & 1.3 & $25-70$ & \multirow{2}{*}{8} & Non classified but possible & \multirow{2}{*}{5.3} \\
\hline & 4.6 & & 8 & 6.25 & & 2 & \\
\hline \multirow{2}{*}{ ASA } & 55 & \multirow{2}{*}{10} & 1.07 & $30-35$ & \multirow{2}{*}{7} & Type 7 & \multirow{2}{*}{7.5} \\
\hline & 5.5 & & 9.25 & 7.75 & & 3 & \\
\hline \multirow{2}{*}{ Polycarbonate } & 72 & \multirow{2}{*}{10} & 1.2 & $35-65$ & \multirow{2}{*}{6} & Type 7 & \multirow{2}{*}{7.6} \\
\hline & 7.2 & & 8.5 & 6 & & 3 & \\
\hline \multirow{2}{*}{ Polypropylene } & 32 & \multirow{2}{*}{9} & 0.9 & $50-100$ & \multirow{2}{*}{4} & Type 5 & \multirow{2}{*}{6.6} \\
\hline & 3.2 & & 10 & 3.5 & & 5 & \\
\hline \multirow{2}{*}{ Metal filled } & $20-30$ & \multirow{2}{*}{4} & 4 & $40-100$ & \multirow{2}{*}{7} & Non classified & \multirow{2}{*}{2.5} \\
\hline & 2.5 & & 1 & 4 & & 1 & \\
\hline \multirow{2}{*}{ PVA } & 78 & \multirow{2}{*}{7} & 1.23 & $35-95$ & \multirow{2}{*}{5} & Type 7 & \multirow{2}{*}{7.0} \\
\hline & 7.8 & & 8.25 & 4.5 & & 3 & \\
\hline
\end{tabular}

\section{Experimental procedures}

For creating a computer prototype of the drone, the Autodesk software FUSION 360 has been used [45]. Main goal was to minimize the mass of the drone housing and to preserve the strength of the structure at the same time. A rotor distance of $580 \mathrm{~mm}$ was chosen. The pre-steps that have been taken into account during the drone model prototyping were: total size of the model, geometry and number of rotors. A sketch with dimensions of $780 \times 758 \times 155 \mathrm{~mm}$ has been generated. Hexa-drone with six rotors was chosen. After getting a general concept, the motors, the propellers, and the battery considering their weight needed to be chosen. The configuration with six brushless motors that are ideally suited for 5 inches $(127 \mathrm{~mm})$ propellers, and for $2 \sim 4$ lipo cell batteries was chosen (Fig. 1). Each motor has a mass of $28 \mathrm{~g}$ and in ideal conditions, using the recommended setups, and generates a thrust of $7.84 \mathrm{~N}$ (5045 prop/4 s). Two battery packs of 4 lipo cells, give power to the motors. The first battery powers the first, the third and the fifth motor, while the second battery powers the remaining second, the fourth and the sixth motor. Each battery weighs $173 \mathrm{~g}$. The 5-inch propellers have a mass of $4.6 \mathrm{~g}$ each, and can be rotated $\mathrm{CW}$ and $\mathrm{CCW}$. The total mass of the drone components, including the speed controller and the hex copter flight controller, was estimated to be $705 \mathrm{~g}$. The total thrust generated by six electric motors is $47 \mathrm{~N}$.

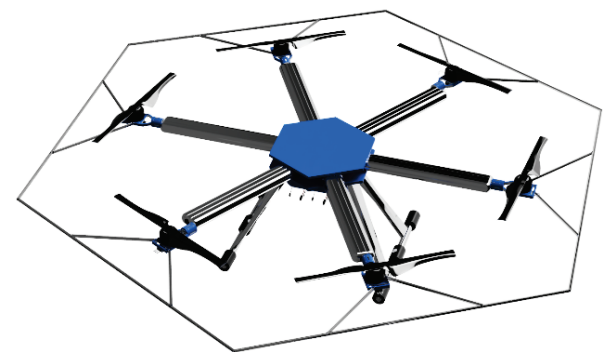

Fig. 1. Rendered view of the 3D CAD model of the drone. Source: authors

The second phase, including all mentioned data, was building the first iteration of the virtual 3D CAD model. 
The FUSION 360 software has two environments which allow better optimization of the created CAD models. These two modalities have the same goal but include different approaches. The first mode is named Shape Optimization that uses the Finite element method (FEM) analysis, generates iterations of the model with respect to the direction of stress movement in the model. The new iteration of the model is within the initial geometry limit. This iteration allows to end up with a better design solution for a model for the same load capacity and safety factors. The downside of this mode, for now, is the impossibility to evaluate multiple materials in a single simulation and it cannot consider model processing methods while generating new designs. The second mode is named Generative Design, and like Shape Optimization, generates multiple iterations of the model with respect to given stresses through FEM analysis. Unlike Shape Optimization, this mode is not limited by the initial geometry, but provides the ability to evaluate multiple materials in a single simulation and can consider model processing methods when generating new designs. A Generative Design has been used to improve the existing model, to reduce the weight and preserve the strength at the same safety factor. Some of the Generative Design results are shown in Fig. 2.
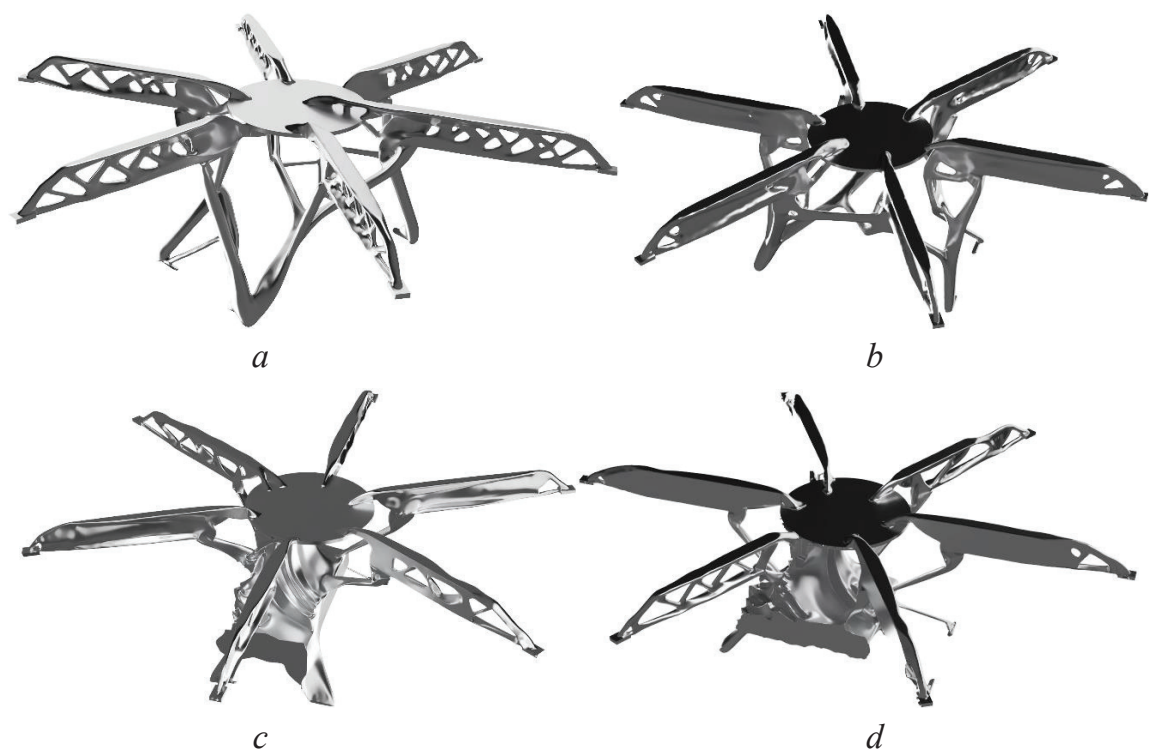

Fig. 2. Some of the Generative Design results; Source: authors. Generative design study outcome: $a-1$ Iteration $61-$ Volume $7.226 \mathrm{e}+6 \mathrm{~mm}^{3} ; b-2$ Iteration $57-$ Volume $9.107 \mathrm{e}+6 \mathrm{~mm}^{3}$; $c-3$ Iteration $46-$ Volume $1.539 \mathrm{e}+7 \mathrm{~mm}^{3} ; d-4$ Iteration $23-$ Volume $4.524 \mathrm{e}+7 \mathrm{~mm}^{3}$

After evaluation of all presented cases, the chosen design is shown in Fig. 3.

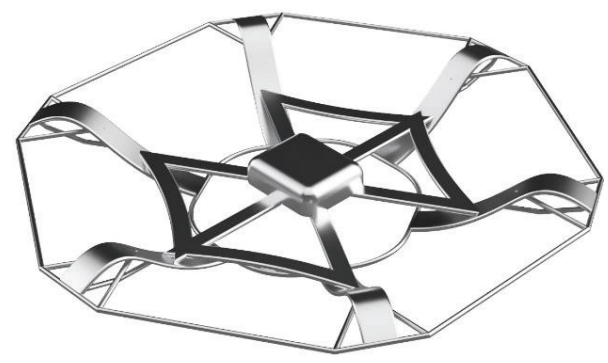

Fig. 3. The chosen design for final 3D CAD model. Source: authors

A 3D model was created, taking into the consideration the new design provided by using Generative Design. When using Polycarbonate as the main material for the housing construction, the weight was estimated to be $586 \mathrm{~g}$. To test the strength and the compactness of the construction FEM analysis was used (Table 3). The goal was to see the static load that the new construction of the model can withstand. The test results are as shown. 
Table 3

FEM analysis result based on static load

Central force on the drone housing

Force on the rotors

F2
20

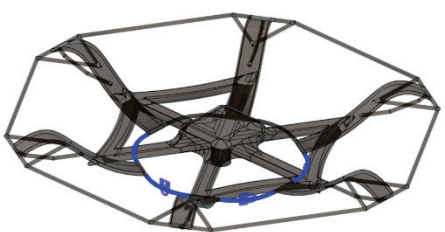

Construction material

Rotor distance

Housing mass

Motor mass

Rest of components mass

Total mass

Motor thrust

Min. Safety Factor

Max. Stress

Max. Displacement
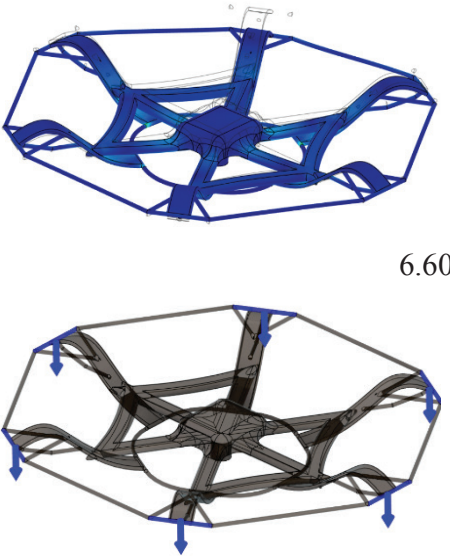

$$
\begin{gathered}
\text { Polycarbonate } \\
0.58 \mathrm{~m} \\
586 \mathrm{~g} \\
168 \mathrm{~g} \\
536 \mathrm{~g} \\
1.29 \mathrm{~kg} \\
47 \mathrm{~N} \\
3.026
\end{gathered}
$$

$6.608 \mathrm{MPa}$

$4.6 \mathrm{~mm}$

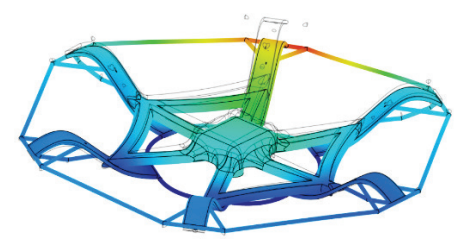

The results of the static FEM analysis showed that the drone housing, made from ABS plastic, can withstand a central force on the drone housing of $70 \mathrm{~N}$, as well as $20 \mathrm{~N}$ of force on each rotor with a safety factor of 3.026. The generative design model has a mass of $586 \mathrm{~g}$, which is significantly less from the mass of the original model that had a mass of $750 \mathrm{~g}$. By getting the original prototype through generative design, the mass was reduced by $22 \%$ conserving structural properties.

\section{Results and discussion}

In this paper a comparison between following UAVs has been conducted: AscTech Hummingbird 1, AscTech Firefly, AscTech Hummingbird 2, AscTech Pelican and our UAV - Prototype 1 . The main parameters that have been considered were rotor distance, take-off weight and electromotor weight. As Fig. 4 represents, Prototype 1 has the largest rotor distance from the observed UAVs of $0.58 \mathrm{~m}$. 


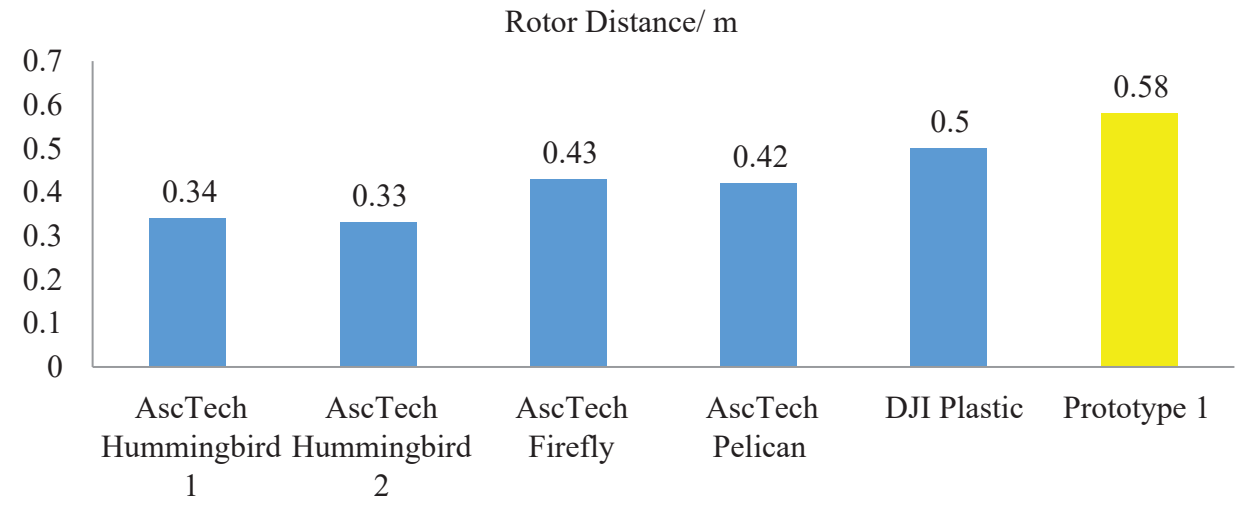

Fig. 4. Rotor distances of compared UAVs

In Fig. 5 the take-off mass of the different types of UAV-s is compared to the take-off mass of the Prototype $1 \mathrm{UAV}$.

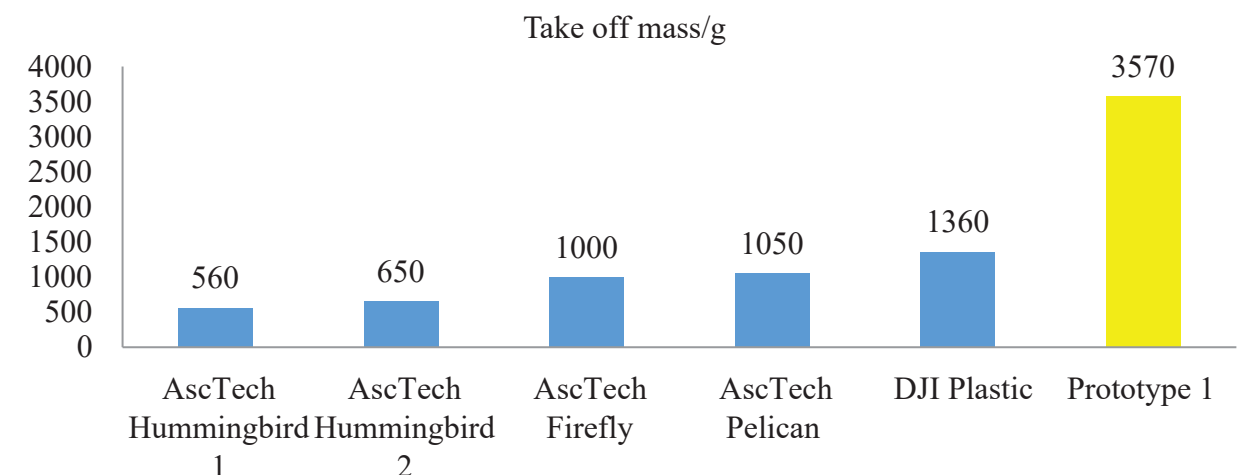

Fig. 5. Take- off mass of compared UAVs

Fig. 6 shows that Prototype1, with electromotor mass of $157.08 \mathrm{~g}$, is approximately in the middle of the range from $88.00 \mathrm{~g}$ (Astec Pelican) to $320.00 \mathrm{~g}$ (AscTech Hummingbird 2).

Electromotor mass/g

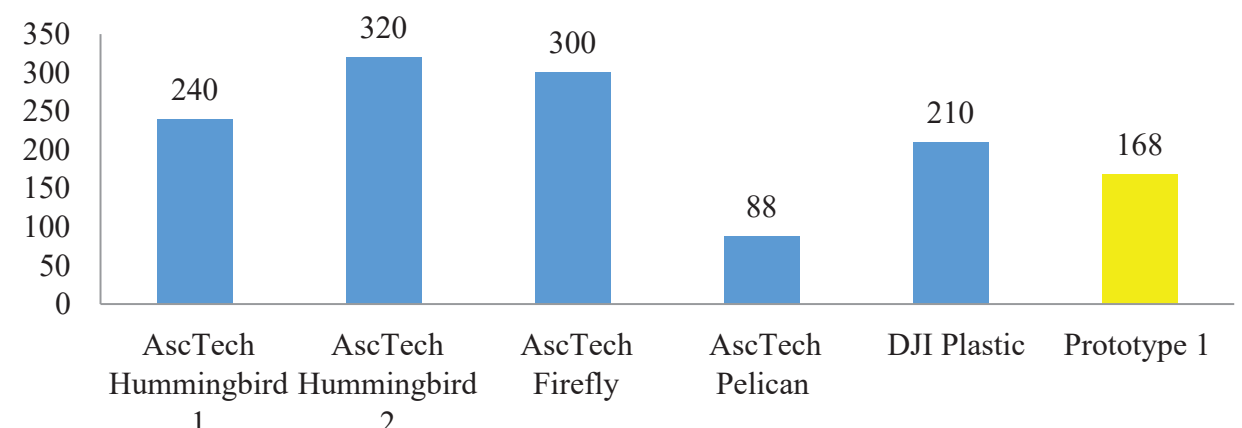

Fig. 6. Electromotor mass of compared UAVs

With the largest rotor distance, and the middle electromotor mass, the Prototype 1 UAV ranges first best with a take-off weight mass of $3570 \mathrm{~g}$. This result confirms the desired goal has been achieved, by proposing a 3D printed drone model with the highest take-off weight mass.

The inherent limitations of this study are the finite set of five UAVs compared. It can be proposed to include some more UAVs in the comparison set for further study.

The finite set of UAVs materials are the disadvantage of the study too, and it should be enlarged by including some more materials in future studies. 
The preliminary study case presented in this paper was based on FEM analysis of static load in order to explore the drone housing durability, max load and find weak points in the construction made by generative design. A more detailed analysis for this application would require dynamic and vibration analysis to better predict UAV behaviour. There is also the problem of making FEM analysis for FDM 3D printing models, because of different parameters specific for this kind of technology such as model ant geometry of infill type, layer adhesion etc. Future studies should take into account previously named differences too.

\section{Conclusions}

In this paper, the synergetic effects of new technologies combining, such as additive manufacturing, FEM analysis and shape optimization/generative design, as well as choosing the best suitable 3D printing material for UAV application has been investigated. Presented approach demonstrated that combination of several new technologies can have a positive impact in the production of UAV prototypes. In addition to reducing the use of non-recyclable materials, this paper's main goals are turned toward economic and ecological efficiency as well. FEM analysis and topology optimization in the designing phase was used to minimize the components mass while preserving structural requirements. Applying additive manufacturing in UAV production can drastically reduce costs and development times. Additive manufacturing also allows for the easy production of components with complex geometry. Merging topology optimization from the designing phase with additive manufacturing, enabled to achieve an optimal balance of strength and mass that results in the UAVs greater take-off weight mass.

Here following UAVs have been compared: AscTech Hummingbird 1, AscTech Firefly, AscTech Hummingbird 2, AscTech Pelican and our UAV, Prototype 1 by following criteria: rotor distance, take-off weight mass and electromotor mass. With the largest rotor distance of $0.58 \mathrm{~m}$ and the middle electromotor mass of $157.08 \mathrm{~g}$. Prototype 1 is first best with a take-off weight mass of $3570 \mathrm{~g}$. This result confirms the desired goal has been achieved, by proposing a 3D printed drone model with the highest take-off weight mass. One important thing in designing a UAV prototype is choosing the right material. UAV industries ordinarily use composite materials that are low in mass, high in strength, fatigue resistance and easy to process. Most of the commercial UAVs today use carbon-fibre-reinforced plastic as the main material (CFRP). One of the goals of this paper was also to choose the best suitable material for 3D printing the drone. Evaluating different materials that can be 3D printed, different properties were taken in the calculation such as ultimate strength, stiffness, durability, printability of the material, and required bed and extruder temperature for printing the selected material. Taking all this into consideration, Polycarbonate proved to be the best choice for 3D printing UAVs. For our future research work, the main topic should be designing the UAV from recycled materials that can help in reducing environmental pollution.

\section{Acknowledgements}

This article was made under the support of DYNAMIC project - 588378-EPP-1-2017-1DE-EPPKA2-KA, towards responsive engineering curricula through Europeanization of dual higher education.

\section{References}

[1] Pacurar, R., Pacurar, A. (2016). Applications of the Selective Laser Melting Technology in the Industrial and Medical Fields. New Trends in 3D Printing. doi: https://doi.org/10.5772/63038

[2] Tuck, C. J., Hague, R. J. M., Ruffo, M., Ransley, M., Adams, P. (2008). Rapid manufacturing facilitated customization. International Journal of Computer Integrated Manufacturing, 21 (3), 245-258. doi: https://doi.org/10.1080/09511920701216238

[3] Horn, T. J., Harrysson, O. L. A. (2012). Overview of Current Additive Manufacturing Technologies and Selected Applications. Science Progress, 95 (3), 255-282. doi: https://doi.org/10.3184/003685012x13420984463047

[4] Additive Manufacturing in Aerospace, Defence \& Space. Trends and Analysis 2016. Available at: https://defencesummits.files. wordpress.com/2016/02/additive-manufacturing-in-defence-and-aerospace-analysis-and-trends-20161.pdf

[5] Huang, S. H., Liu, P., Mokasdar, A., Hou, L. (2012). Additive manufacturing and its societal impact: a literature review. The International Journal of Advanced Manufacturing Technology, 67 (5-8), 1191-1203. doi: https://doi.org/10.1007/s00170-012-4558-5 
[6] Mellor, S., Hao, L., Zhang, D. (2014). Additive manufacturing: A framework for implementation. International Journal of Production Economics, 149, 194-201. doi: https://doi.org/10.1016/j.ijpe.2013.07.008

[7] Ponche, R., Kerbrat, O., Mognol, P., Hascoet, J.-Y. (2014). A novel methodology of design for Additive Manufacturing applied to Additive Laser Manufacturing process. Robotics and Computer-Integrated Manufacturing, 30 (4), 389-398. doi: https:// doi.org/10.1016/j.rcim.2013.12.001

[8] Bici, M., Brischetto, S., Campana, F., Ferro, C. G., Seclì, C., Varetti, S. et. al. (2018). Development of a multifunctional panel for aerospace use through SLM additive manufacturing. Procedia CIRP, 67, 215-220. doi: https://doi.org/10.1016/ j.procir.2017.12.202

[9] Mieloszyk, J., Tarnowski, A., Kowalik, M., Perz, R., Rzadkowski, W. (2019). Preliminary design of 3D printed fittings for UAV. Aircraft Engineering and Aerospace Technology, 91 (5), 756-760. doi: https://doi.org/10.1108/aeat-07-2018-0182

[10] Brischetto, S., Ciano, A., Ferro, C. G. (2016). A multipurpose modular drone with adjustable arms produced via the FDM additive manufacturing process. Curved and Layered Structures, 3 (1). doi: https://doi.org/10.1515/cls-2016-0016

[11] Turner, I. L., Harley, M. D., Drummond, C. D. (2016). UAVs for coastal surveying. Coastal Engineering, 114, $19-24$. doi: https://doi.org/10.1016/j.coastaleng.2016.03.011

[12] Gago, J., Douthe, C., Coopman, R. E., Gallego, P. P., Ribas-Carbo, M., Flexas, J. et. al. (2015). UAVs challenge to assess water stress for sustainable agriculture. Agricultural Water Management, 153, 9-19. doi: https://doi.org/10.1016/ j.agwat.2015.01.020

[13] Zhang, C., Kovacs, J. M. (2012). The application of small unmanned aerial systems for precision agriculture: a review. Precision Agriculture, 13 (6), 693-712. doi: https://doi.org/10.1007/s11119-012-9274-5

[14] Ventura, D., Bruno, M., Jona Lasinio, G., Belluscio, A., Ardizzone, G. (2016). A low-cost drone based application for identifying and mapping of coastal fish nursery grounds. Estuarine, Coastal and Shelf Science, 171, 85-98. doi: https:// doi.org/10.1016/j.ecss.2016.01.030

[15] Zhang, J., Hu, J., Lian, J., Fan, Z., Ouyang, X., Ye, W. (2016). Seeing the forest from drones: Testing the potential of lightweight drones as a tool for long-term forest monitoring. Biological Conservation, 198, 60-69. doi: https://doi.org/10.1016/ j.biocon.2016.03.027

[16] Spiess, T., Bange, J., Buschmann, M., Vörsmann, P. (2007). First application of the meteorological Mini-UAV 'M2AV'. Meteorologische Zeitschrift, 16 (2), 159-169. doi: https://doi.org/10.1127/0941-2948/2007/0195

[17] Rao, B., Gopi, A. G., Maione, R. (2016). The societal impact of commercial drones. Technology in Society, 45, 83-90. doi: https://doi.org/10.1016/j.techsoc.2016.02.009

[18] Clarke, R., Moses, L. B. (2014). The regulation of civilian drones' impacts on public safety. Computer Law \& Security Review, 30 (3), 263-285. doi: https://doi.org/10.1016/j.clsr.2014.03.007

[19] Pensieri, M. G., Garau, M., Barone, P. M. (2020). Drones as an Integral Part of Remote Sensing Technologies to Help Missing People. Drones, 4 (2), 15. doi: https://doi.org/10.3390/drones4020015

[20] Fennelly, L. J., Perry, M. A. (2020). Unmanned Aerial Vehicle (Drone) Usage in the 21st Century. The Professional Protection Officer, 183-189. doi: https://doi.org/10.1016/b978-0-12-817748-8.00050-x

[21] Fraga-Lamas, P., Ramos, L., Mondéjar-Guerra, V., Fernández-Caramés, T. M. (2019). A Review on IoT Deep Learning UAV Systems for Autonomous Obstacle Detection and Collision Avoidance. Remote Sensing, 11 (18), 2144. doi: https:// doi.org/10.3390/rs11182144

[22] Lu, M., Liao, X., Yue, H., Huang, Y., Ye, H., Xu, C., Huang, S. (2020). Optimizing distribution of droneports for emergency monitoring of flood disasters in China. Journal of Flood Risk Management, 13 (1). doi: https://doi.org/10.1111/jfr3.12593

[23] Barone, P. M., Wueste, E., Hodges, R. (2020). Remote Sensing Materials for a Preliminary Archaeological Evaluation of the Giove Countryside (Terni, Italy). Remote Sensing, 12 (12), 2023. doi: https://doi.org/10.3390/rs12122023

[24] Flynn, E. P. (2013). Low-cost approaches to UAV design using advanced manufacturing techniques. 2013 IEEE Integrated STEM Education Conference (ISEC). doi: https://doi.org/10.1109/isecon.2013.6525199

[25] Gruen, A. (2012). Unmanned Aerial Vehicles - from toys to tools. GEO Informatics, 14-16. Available at: https:// www.academia.edu/29948855/Unmanned_aerial_vehicles_from_toys_to_tools

[26] Wu, Q., Liu, L., Zhang, R. (2019). Fundamental Trade-offs in Communication and Trajectory Design for UAV-Enabled Wireless Network. IEEE Wireless Communications, 26 (1), 36-44. doi: https://doi.org/10.1109/mwc.2018.1800221

[27] Ping, J. T. K., Ling, A. E., Quan, T. J., Dat, C. Y. (2012). Generic unmanned aerial vehicle (UAV) for civilian application-A feasibility assessment and market survey on civilian application for aerial imaging. 2012 IEEE Conference on Sustainable Utilization and Development in Engineering and Technology (STUDENT). doi: https://doi.org/10.1109/student.2012.6408421

[28] Willems, D. (2020). Cargo Transportation takes drone technologies to the next level. UMS SKELDAR. Available at: https:// umsskeldar.aero/cargo-transportation-takes-drone-technologies-to-the-next-level/ 
[29] Hader, M., Baur, S. (2019). Cargo drones: The future of parcel delivery. Roland Berger GmbH. Available at: https:// www.rolandberger.com/en/Point-of-View/Cargo-drones-The-future-of-parcel-delivery.html

[30] Pounds, P. E. I. (2012). Paper plane: towards disposable low-cost folded cellulose-substrate UAVs. Australasian Conf. on Robotics and Automation, ACRA. Victoria University of Wellington, New Zealand.

[31] Pounds, P. E. I., Singh, S. P. N. (2013). Integrated electro-aeromechanical structures for low-cost, self-deploying environment sensors and disposable UAVs. 2013 IEEE International Conference on Robotics and Automation. doi: https://doi.org/10.1109/ icra.2013.6631210

[32] Junk, S., Côté, S. (2012). Energy and material efficiency in additive manufacturing using 3D printing. Proceedings of the 10th Global Conference on Sustainable Manufacturing. Istanbul.

[33] Junk, S., Schröder, W. (2016). Application of Sustainable Design in Additive Manufacturing of an Unmanned Aerial Vehicle. Smart Innovation, Systems and Technologies, 375-385. doi: https://doi.org/10.1007/978-3-319-32098-4_32

[34] Gregorski, M. (2019). Analysis of international law on Unmanned Aerial Vehicles through the prism of European Union law. Przegląd Europejski, 4, 73-93. doi: https://doi.org/10.5604/01.3001.0013.3455

[35] Ferro, C., Grassi, R., Seclì, C., Maggiore, P. (2016). Additive Manufacturing Offers New Opportunities in UAV Research. Procedia CIRP, 41, 1004-1010. doi: https://doi.org/10.1016/j.procir.2015.12.104

[36] Deaton, J. D., Grandhi, R. V. (2013). A survey of structural and multidisciplinary continuum topology optimization: post 2000. Structural and Multidisciplinary Optimization, 49 (1), 1-38. doi: https://doi.org/10.1007/s00158-013-0956-z

[37] Grodzki, W., Łukaszewicz, A. (2015). Design and manufacture of umanned aerial vehicles (UAV) wing structure using composite materials. Materialwissenschaft Und Werkstofftechnik, 46 (3), 269-278. doi: https://doi.org/10.1002/mawe.201500351

[38] Borchardt, J. K. (2004). Unmanned aerial vehicles spur composites use. Reinforced Plastics, 48 (4), 28-31. doi: https:// doi.org/10.1016/s0034-3617(04)00194-8

[39] Soutis, C. (2005). Fibre reinforced composites in aircraft construction. Progress in Aerospace Sciences, 41 (2), $143-151$. doi: https://doi.org/10.1016/j.paerosci.2005.02.004

[40] Simsiriwong, J., Sullivan, R. W. (2012). Experimental Vibration Analysis of a Composite UAV Wing. Mechanics of Advanced Materials and Structures, 19 (1-3), 196-206. doi: https://doi.org/10.1080/15376494.2011.572248

[41] Goh, G. D., Agarwala, S., Goh, G. L., Dikshit, V., Sing, S. L., Yeong, W. Y. (2017). Additive manufacturing in unmanned aerial vehicles (UAVs): Challenges and potential. Aerospace Science and Technology, 63, 140-151. doi: https://doi.org/10.1016/ j.ast.2016.12.019

[42] Mosaddek, A., Kommula, H. K. R., Gonzalez, F. (2018). Design and Testing of a Recycled 3D Printed and Foldable Unmanned Aerial Vehicle for Remote Sensing. 2018 International Conference on Unmanned Aircraft Systems (ICUAS). doi: https:// doi.org/10.1109/icuas.2018.8453284

[43] Gardiner, G. (2016). 3D printed composite parts provide solution for UAV. CompositesWorld. Available at: https:// www.compositesworld.com/articles/3d-printed-composite-parts-provide-solution-for-uav

[44] Boissonneault, T. (2019). Filamentive releases 100\% recycled ONE PET 3D printing filament. 3D Printing Media Network. Available at: https://www.3dprintingmedia.network/filamentive-one-pet-recycled-filament/

[45] Autodesk Fusion 360: 3D CAD, CAM, CAE \& PCB Cloud-Based Software. Available at: https://www.autodesk.com/products/ fusion-360/overview 